\title{
Utilização de monoamônio fosfato em rações com elevado teor de polpa cítrica para cordeiros em confinamento
}

\section{Gustavo Henrique Rodrigues ${ }^{1}$, Ivanete Susin², Alexandre Vaz Pires ${ }^{2}$, Mário Adriano Ávila Queiroz $^{1}$, Rafael Camargo do Amaral ${ }^{1}$, Marcos Vinicius Biehl ${ }^{1}$, Renato Shinkai Gentil ${ }^{1}$, Evandro Maia Ferreira ${ }^{1}$}

\footnotetext{
1 Pós-graduação em Ciência Animal e Pastagens - ESALQ/USP - Piracicaba, SP.

2 Departamento de Zootecnia - ESALQ/USP - Piracicaba, SP.
}

RESUMO - Objetivou-se com esta pesquisa avaliar os efeitos da inclusão de monoamônio fosfato (MAP) em rações com alta proporção de concentrado contendo polpa cítrica sobre o desempenho e as características de carcaça de cordeiros em confinamento. Vinte e quatro cordeiros Santa Inês (26,4 kg de peso corporal e 125 dias de idade, em média) foram distribuídos em delineamento experimental de blocos completos casualizados, definidos de acordo com o peso e a idade no início do experimento. As rações foram isonitrogenadas, continham $70 \%$ de polpa cítrica na MS e tiveram a adição de 0 ; 0,3; 0,6 e 0,9\% de MAP, correspondendo aos tratamentos CON, 0,3MAP, 0,6MAP e 0,9MAP, respectivamente. Houve diminuição linear no consumo de matéria seca e ganho diário médio de peso com a inclusão de MAP na ração, sem alteração nos parâmetros de carcaça avaliados. A utilização de MAP como fonte de fósforo em rações contendo polpa cítrica afeta negativamente o desempenho de cordeiros em confinamento.

Palavras-chave: carcaça, desempenho, ovinos, Santa Inês, subproduto

\section{Monoammonium phosphate in diets with high level of citrus pulp fed to feedlot lambs}

\begin{abstract}
The objective of this experiment was to evaluate the effects of adding monoammonium phosphate (MAP) in high concentrate diets containing citrus pulp on feedlot lamb performance and carcass characteristics. Twenty four Santa Ines lambs (26.4 kg of initial body weight and $125 \mathrm{~d}$ old) were penned individually and used in a randomized complete block design according to body weight and age at beginning of the trial. Diets were formulated to provide a similar amount of crude protein and contained $70 \%$ of citrus pulp on a DM basis. MAP was added at $0,0.3,0.6$, and $0.9 \%$ of the diet DM corresponding to the experimental treatments CON, 0.3MAP, 0.6MAP, and 0.9MAP, respectively. There was a linear decrease in dry matter intake and average daily gain, although no changes on carcass measures were observed. The use of MAP in citrus pulp diets affects lamb growth negatively.
\end{abstract}

Key Words: by-products, carcass, performance, Santa Inês, sheep

\section{Introdução}

A maioria dos sistemas intensivos de produção de cordeiros possui como premissa a utilização de rações com grande proporção de concentrado, sendo o milho a fonte energética mais usada. A introdução de fontes alternativas em substituição total ou parcial ao milho, como a polpa cítrica, tem sido adotada com sucesso nesse sistema (Rodrigues et al., 2008a). Entretanto, este subproduto possui como característica elevada quantidade de cálcio em relação ao fósforo, resultando no desbalanceamento da relação desses minerais.
Além do teor de fósforo na dieta, a relação cálcio:fósforo interfere na absorção do fósforo pelo organismo (McDowell, 1992), provavelmente, em função da solubilidade dos sais resultantes da interação entre os minerais (Field et al., 1983). Estudos com ovinos sugerem uma proporção adequada entre cálcio e fósforo para melhor absorção de fósforo (Salviano \& Vitti, 1998) e desempenho animal satisfatório (Zahari et al., 1990). Assim, a suplementação de fósforo para cordeiros em confinamento, torna-se importante na utilização de polpa cítrica para a nutrição adequada dessa categoria animal. 
O fósforo é um mineral que pode constituir até $1 \%$ do peso corporal dos animais, sendo encontrado principalmente nos ossos e dentes, além de estar envolvido com o metabolismo, participando no transporte de ácidos graxos, absorção e deposição de gorduras e formação de proteínas. Além disso, o fósforo participa da composição dos ácidos nucléicos (DNA e RNA), atua na manutenção da pressão osmótica e equilíbrio ácido-básico (McDowell, 1992).

Nos animais ruminantes, o fósforo tem função adicional, que é atender às exigências dos microrganismos ruminais, sendo que sua deficiência pode prejudicar a síntese de proteína microbiana e a digestão de nutrientes (Witt \& Owens, 1983). Adicionalmente, os estudos referentes a esse mineral têm o objetivo de minimizar o impacto poluidor do fósforo no meio ambiente.

Várias fontes de fósforo estão disponíveis no mercado para o uso em rações de ruminantes. Contudo, a presença de xenobióticos, metais pesados e contaminantes (Marçal et al., 2003), além da biodisponibilidade e custo dessas fontes são fatores que determinam a utilização desses.

Com a possibilidade de utilização de fontes alternativas de fósforo, vários estudos têm sido realizados no intuito de pesquisar a viabilidade de utilização dessas fontes minerais. O fosfato de rocha de Araxá, o superfosfato triplo e o monoamônio fosfato (MAP) são as fontes mais estudadas no sentido de verificar a possibilidade de substituir o fosfato bicálcico, por apresentarem baixa quantidade de cálcio e no intuito de reduzir custos com a suplementação mineral.

O MAP aparece nesse contexto como fonte de fósforo que possui quantidade de flúor dentro dos limites sugeridos como seguros, não causando intoxicação nos animais
(Barreto et al., 2009) e apresenta boa absorção do mineral em relação à outras fontes, sendo rápida sua distribuição nos tecidos (Vitti et al., 1989). No entanto, não há informações relacionadas aos teores de inclusão de MAP em rações para cordeiros confinados alimentados com polpa cítrica.

O objetivo neste estudo foi avaliar o desempenho e as características de carcaça de cordeiros da raça Santa Inês alimentados com teores crescentes de MAP em rações contendo elevada proporção de polpa cítrica.

\section{Material e Métodos}

O experimento foi conduzido no Sistema Intensivo de Produção de Ovinos e Caprinos (SIPOC) do Departamento de Zootecnia da Escola Superior de Agricultura "Luiz de Queiroz” (USP/ESALQ), em Piracicaba, São Paulo. Vinte e quatro cordeiros da raça Santa Inês com peso inicial médio de $26,4( \pm 5,8) \mathrm{kg}$ e idade média de $125( \pm 11)$ dias foram confinados por 56 dias, em baias cobertas com piso de concreto, cocho e bebedouros, sendo distribuído um animal por baia e seis baias por tratamento.

As rações foram constituídas de $5 \%$ de volumoso (bagaço de cana-de-açúcar in natura) e 95\% de concentrado na matéria seca (MS). O MAP foi incluído na proporção de 0; 0,3; 0,6 e 0,9\% da MS na ração (Tabela 1).

Em função da característica da ração (90\% MS), a alimentação foi fornecida três vezes/semana, ad libitum, e as sobras pesadas semanalmente para a determinação do consumo diário de MS por baia.

Após o período de avaliação do desempenho, os cordeiros foram pesados depois de jejum de sólidos de 16 horas e, em seguida, abatidos segundo as normas descritas

Tabela 1- Proporção dos ingredientes e composição química das rações experimentais (\% na MS)

\begin{tabular}{|c|c|c|c|c|}
\hline \multirow[t]{2}{*}{ Ingrediente } & \multicolumn{4}{|c|}{ Tratamento $^{1}$} \\
\hline & CON & $0,3 \mathrm{MAP}$ & $0,6 \mathrm{MAP}$ & 0,9MAP \\
\hline Bagaço de cana in natura & 5,0 & 5,0 & 5,0 & 5,0 \\
\hline Farelo de algodão & 22,8 & 22,4 & 21,9 & 21,3 \\
\hline Ureia & 0,5 & 0,5 & 0,5 & 0,5 \\
\hline Cloreto de amônio & 0,5 & 0,5 & 0,5 & 0,5 \\
\hline Monoamônio fosfato (MAP) & 0,0 & 0,3 & 0,6 & 0,9 \\
\hline \multicolumn{5}{|l|}{ Composição química } \\
\hline Matéria seca & 87,6 & 84,5 & 86,5 & 83,9 \\
\hline Proteína bruta & 19,4 & 20,4 & 20,6 & 20,1 \\
\hline Fibra em detergente neutro & 25,8 & 26,0 & 25,1 & 25,0 \\
\hline Matéria orgânica & 94,7 & 92,4 & 93,5 & 92,7 \\
\hline Matéria mineral & 5,7 & 7,6 & 6,5 & 7,3 \\
\hline
\end{tabular}


no Regulamento da Inspeção Industrial e Sanitária de Produtos de Origem Animal - RIISPOA (Brasil, 1997). As carcaças foram seccionadas longitudinalmente em duas meias-carcaças e pesadas individualmente, obtendo-se o peso de carcaça quente e após 24 horas, à temperatura de $2{ }^{\circ} \mathrm{C}$, o peso das carcaças frias. Para a determinação do rendimento de carcaça quente (RCQ), rendimento de carcaça fria (RCF) e perda por resfriamento (PR) foram utilizadas as seguintes fórmulas:

$$
\begin{aligned}
& \mathrm{RCQ}=(\mathrm{PCQ} / \mathrm{PVA}) \times 100, \\
& \mathrm{RCF}=(\mathrm{PCF} / \mathrm{PVA}) \times 100, \\
& \mathrm{PR}=[(\mathrm{PCQ}-\mathrm{PCF}) / \mathrm{PCQ}] \times 100 .
\end{aligned}
$$

em que:

$$
\text { PCQ = peso da carcaça quente }
$$$$
\text { PVA = peso vivo de abate }
$$$$
\text { PCF = peso da carcaça fria }
$$

A meia-carcaça direita foi escolhida para a tomada da medida de espessura de gordura (EG) e área de olho-delombo (AOL). A medida da EG foi tomada entre a $12^{2}$ e $13^{\text {a }}$ costela da parte posterior da meia-carcaça por meio de paquímetro digital graduado em milímetros. A AOL foi desenhada no músculo exposto logissimus dorsi mediante papel vegetal e posteriormente mensurada por meio de planímetro com resultado em $\mathrm{cm}^{2}$.

As amostras de ração fornecida, sobras e ingredientes individuais da ração foram pré-secadas em estufa com ventilação de ar forçado, reguladas à temperatura de $55^{\circ} \mathrm{C}$, pelo período de 72 horas (Campos et al., 2004). Em seguida, todas as amostras foram moídas em moinho do tipo Wiley provido de peneira de crivos de $1 \mathrm{~mm}$ de diâmetro. O teor de matéria seca (MS) foi determinado em estufa a $105{ }^{\circ} \mathrm{C}$ durante o período de 12 horas de exposição, e de cinzas $(\mathrm{MM})$ em mufla à temperatura de $550{ }^{\circ} \mathrm{C}$ durante 3 horas (AOAC, 1990). A matéria orgânica (MO) das amostras foi calculada pela diferença entre a MS e a MM. O teor de fibra em detergente neutro (FDN) foi determinado com o uso de sulfito de sódio com a adição de enzima amilase termoestável (van Soest et al., 1991), com auxílio do analisador de fibra modelo ANKON Fiber Analyser (ANKON ${ }^{\circledR}$ Technology Corp.), descrito por Holden (1999). Os valores obtidos foram corrigidos para o teor de MS a $105{ }^{\circ} \mathrm{C}$ das amostras e MM, após a incineração dos saquinhos.

A determinação de nitrogênio total foi realizada com base na combustão das amostras pelo analisador da marca LECO $^{\circledR}$ (Wiles et al., 1998), modelo FP-528 com temperatura para combustão de $835^{\circ} \mathrm{C}$. O teor de proteína bruta (PB) foi obtido por meio da multiplicação do teor de nitrogênio total por 6,25.

O delineamento experimental foi o de blocos completos casualizados com quatro tratamentos e seis repetições, sendo os blocos definidos pelo peso e pela idade inicial dos animais. Os dados dos experimentos foram analisados pelo procedimento GLM do pacote estatístico SAS (2002). As médias das variáveis foram obtidas pelo comando LSMEANS e para as que obtiveram respostas significativas $(\mathrm{P}<0,05)$, utilizou-se o teste para polinômios ortogonais (linear e quadrático). Foi utilizado o seguinte modelo estatístico:

$$
\mathrm{Y}_{\mathrm{ijk}}=\mathrm{M}+\mathrm{B}_{\mathrm{i}}+\mathrm{T}_{\mathrm{j}}+\mathrm{E}_{\mathrm{ijk}}
$$

em que: $\mathrm{M}=$ média geral; $\mathrm{B}_{\mathrm{i}}=$ efeito do bloco; $\mathrm{T}_{\mathrm{j}}=$ efeito do tratamento; $\mathrm{E}_{\mathrm{ijk}}=$ efeito aleatório

\section{Resultados e Discussão}

A adição de MAP nas rações experimentais resultou em decréscimo linear no ganho diário médio (GDM) $\left(y=236,58-72,024 x ; R^{2}=0,21\right)(P<0,05)$ e consumo de MS (CMS) $(\mathrm{kg} / \mathrm{dia})\left(\mathrm{y}=1,1311-0,2349 \mathrm{x} ; \mathrm{R}^{2}=0,16\right)(\mathrm{P}<0,01)$ (Tabela 2). No entanto, não houve efeito $(\mathrm{P}>0,05)$ dos tratamentos na conversão alimentar (CA) dos animais e na determinação dos parâmetros de carcaça (rendimento de carcaça quente, perda por resfriamento, área de olho-delombo e espessura de gordura).

A inclusão de MAP na ração ajustou a proporção entre cálcio e fósforo para a melhor relação possível entre os minerais, considerando que a relação ideal é 2:1 e um dos fatores que pode exercer efeito na absorção de fósforo é a relação cálcio:fósforo(Tabela1). Field etal.(1983) investigaram o efeito de diferentes proporções de cálcio e fósforo, variando de 0,6 a 3,6, na absorção do fósforo em ovinos e concluíram que as dietas contendo maior proporção de cálcio a absorção de fósforo foi reduzida em $18 \%$, o que pode ser explicado em parte pela formação de sais com baixa solubilidade.

Da mesma forma, Salviano \& Vitti (1998), em estudos com ovinos que receberam rações com diferentes relações cálcio e fósforo na dieta $(0,75: 1 ; 1,5: 1$ e 3:1), observaram que a maior absorção de fósforo ocorreu com a proporção 1,5:1. Por outro lado, baixa relação entre cálcio e fóforo é condição para a ocorrência de distúrbio metabólico comum em ovinos denominado urolitíase ou cálculo urinário (Emerick \& Embry, 1963), e isso sugere a existência de uma proporção adequada para a nutrição de cordeiros em confinamento.

Entretanto, mesmo com a melhor proporção cálcio:fósforo de 2,5 da ração experimental 0,9MAP obtida neste estudo (Tabela1), houve diminuição linear no CMS e GDM dos cordeiros, sugerindo que o efeito negativo observado da adição de MAP pode ser atribuída à fonte de fósforo.

O MAP contém pouco cálcio e é muito reativo (Nicodemo \& Moraes, 2000), por isso, pode ser uma boa fonte alternativa de fósforo em dietas ricas em cálcio, como 
aquelas contendo grande proporção de polpa cítrica. Além disso, a biodisponibilidade de fósforo é um requisito que o MAP atende prontamente para sua utilização. Vitti et al. (1989), comparando fontes de fósforo observaram que o MAP foi metabolizado mais rapidamente que os demais, apresentando rápida distribuição nos tecidos, o que foi confirmado por Vitti et al. (1992), trabalhando com ovinos, utilizando a técnica de radioisótopos, onde observaram alta disponibilidade biológica para o MAP (59\%). Reid (1980) menciona que o fósforo de fertilizantes fosfatados como o supertriplo e MAP é altamente disponível e que o uso dessas fontes na suplementação de animais domésticos é, na verdade, mais limitado pelo teor de flúor do que pela absorção de fósforo. Entretanto, segundo Barreto et al. (2009), o MAP é a fonte de fósforo que possui o teor de flúor adequado para evitar toxidez aos animais, justificando sua utilização como fonte alternativa ao fosfato bicálcico.

Aceitabilidade parece ser o fator que se opõe contra a utilização de MAP como fonte de fósforo, o que explica os resultados deste trabalho (Tabela 2). A redução do consumo de MS em dietas contendo grande proporção de polpa cítrica com a adição de MAP na ração foi verificada por Rodrigues et al. (2008a). Ao substituírem o milho por PCD (polpa cítrica desidratada), os autores observaram queda de consumo de cordeiros alimentados com rações contendo 46,1 e 68,4\% de PCD, coincidentemente com a adição de 0,5 e 1,3\% de MAP, respectivamente em relação à dieta contendo 23,7\% de PCD, mas com a ausência da fonte de fósforo. A adição de MAP no estudo citado na ordem de 0,5 e 1,3\% de MAP significou redução de 14,7 e 16,3\% no consumo de MS e 23,8 e 37,5\% no GDM, respectivamente em relação à dieta contendo PCD sem adição do suplemento mineral, justificando a redução linear das variáveis deste estudo (Tabela 2).

Da mesma forma, Durand et al. (1976) ao compararem MAP e ureia como fonte de nitrogênio para a síntese de proteína microbiana e a influência desses ingredientes na atividade da flora ruminal verificaram menor aceitabilidade em cordeiros alimentados com rações contendo 4\% de MAP. Os autores atribuíram esse efeito aos menores valores de pH ruminal, maior concentração de nitrogênio amoniacal e reduzida formação de ácidos graxos de cadeia curta para essa ração experimental, justificando a redução linear do consumo de MS e consequentemente do GDM conforme adição de MAP deste estudo (Tabela 2). Estes resultados são também condizentes com os de Fisher (1978), que apesar de não encontrar diferença no consumo de MS quando comparou os fosfatos dicálcio, monocálcio, monosódio e monoamônio, observou menor ingestão de MS digestível e reduzida digestibilidade de FDA da ração quando esta continha MAP comparado as demais fontes de fósforo.

Em suma, mesmo com a menor inclusão de MAP (0,3\%) na ração houve efeito da adição da fonte no desempenho dos cordeiros, sugerindo que a utilização de MAP se faz desnecessária em rações contendo polpa cítrica para cordeiros em terminação. No entanto, é preciso considerar que os animais foram alimentados por 56 dias, portanto, situação que não pode ser aplicada a animais recebendo dietas desbalanceadas em cálcio e fósforo por longos períodos.

O peso de abate dos animais foi reflexo do consumo de MS e GDM, o qual diminuiu linearmente $(\mathrm{P}<0,01)$ conforme adição de MAP na ração. Isso resultou na diminuição

Tabela 2 - Desempenho e características de carcaça de cordeiros Santa Inês alimentados com adição crescente de MAP nas rações

\begin{tabular}{|c|c|c|c|c|c|c|c|}
\hline Variável $^{1}$ & \multicolumn{4}{|c|}{ Tratamento $^{2}$} & $\mathrm{EPM}^{3}$ & \multicolumn{2}{|c|}{ Efeito $^{4}$} \\
\hline Peso inicial, kg & 26,7 & 26,5 & 26,5 & 26,0 & 0,57 & - & - \\
\hline GDM, g & 239 & 205 & 204 & 167 & 0,02 & $<0,05$ & NS \\
\hline \multicolumn{8}{|l|}{ CMS } \\
\hline $\mathrm{kg} / \mathrm{dia}$ & 1,2 & 1,0 & 1,0 & 0,9 & 0,04 & $<0,01$ & NS \\
\hline CA, kg MS/kg ganho & 4,8 & 4,7 & 5,0 & 5,3 & 0,23 & NS & NS \\
\hline PCQ, kg & 21,3 & 19,8 & 20,3 & 19,3 & 0,47 & $<0,05$ & NS \\
\hline PCF, kg & 20,6 & 19,3 & 19,6 & 18,7 & 0,46 & $<0,05$ & NS \\
\hline RCQ, \% & 50,3 & 50,3 & 51,1 & 51,4 & 0,61 & NS & NS \\
\hline PR, \% & 3,2 & 3,1 & 3,3 & 3,0 & 0,33 & NS & NS \\
\hline $\mathrm{AOL}, \mathrm{cm}^{2}$ & 14,8 & 13,9 & 14,0 & 14,2 & 0,44 & NS & NS \\
\hline
\end{tabular}


$(\mathrm{P}<0,05)$ também linear nos pesos de carcaça fria e quente, entretanto, não houve efeito para os demais parâmetros de características de carcaça.

Os valores médios verificados, para as variáveis: peso ao abate (PA), rendimento de carcaça quente (RCQ), perda por resfriamento (PR), área de olho-de-lombo (AOL) e espessura de gordura (EG) foram: 37,9 kg; 50,8\%; 3,2\%, $14,2 \mathrm{~cm}^{2}$ e $2,3 \mathrm{~mm}$, respectivamente. Rodrigues et al. (2008b) avaliando esses parâmetros na carcaça de cordeiros alimentados com ração contendo 68,4\% de PCD verificaram valores de $32,5 \mathrm{~kg} ; 49,8 \%$; 2,9\%, $12,7 \mathrm{~cm}^{2}$ e $1,5 \mathrm{~mm}$, respectivamente. Caparra et al. (2007) encontraram valores menores para PA (28,8 kg), PR (2,0\%) e RCQ $(48,7 \%)$, avaliando as características das carcaças de cordeiros Merino Italiano recebendo 45\% de polpa cítrica desidratada ao sol. Pereira et al. (2007) encontraram 44,7\% de RCQ para cordeiros Santa Inês abatidos com 32,7 kg alimentados com $45 \%$ de polpa cítrica úmida prensada. A diferença de valores em relação aos reportados na literatura, que também utilizaram cordeiros alimentados com subprodutos da indústria citrícola, provavelmente pode ser justificada pelo maior peso ao abate desse estudo comparado aos demais trabalhos.

\section{Conclusões}

A utilização de monoamônio fosfato como fonte de fósforo em rações contendo alta proporção de polpa cítrica reduz o desempenho de cordeiros em confinamento. Outras fontes de fósforo devem ser estudadas no intuito de manter adequada a relação cálcio:fósforo em dietas ricas em polpa cítrica sem prejudicar o desempenho animal.

\section{Referências}

ASSOCIATION OF OFFICIAL ANALYTICAL CHEMISTS - AOAC. Official methods of analysis. 15.ed. Washington, D.C.: 1990. 1298p.

BARRETO, J.C.; BRANCO, A.F.; SANTOS, G.T. et al. Avaliação dos efeitos de fontes de fósforo na dieta sobre parâmetros do meio ruminal e eficiência de síntese microbiana, digestibilidade dos nutrientes e fósforo plasmático em bovinos. Revista Brasileira de Zootecnia, v.38, n.4, p.760-769, 2009.

BRASIL. Ministério da Agricultura. Decreto lei n. 2.244, de 5 junho 1997. Regulamento da inspeção industrial e sanitária de produtos de origem animal. Brasília, 1997. 204p.

CAMPOS, F.P.; NUSSIO, C.M.B.; NUSSIO, L.G. Métodos de análises de alimentos. Piracicaba: FEALQ, 2004. 135p.

CAPARRA, P.; FOTI, F.; SCERRA, M. et al. Solar-dried citrus pulp as an alternative energy source in lamb diets: Effects on growth and carcass and meat quality. Small Ruminant Research, v.40, n.3, p.303-311, 2007.

DURAND, M.; FORET, R.; DUMAY, C. et al. Utilisation du phosphate monoammonique chez le mouton. II.- Influence sur le métabolisme azoté de la microflore du rúmen. Annales de Zootechnie, v.25, p.119-134, 1976.

EMERICK, R.J.; EMBRY, L.B. Calcium and phosphorus levels related to the development of phosphate urinary calculi in sheep. Journal of Animal Science, v.22, p.510-513, 1963.

FIELD, A.C.; KAMPHUES, J.; WOOLIAMS, J.A. The effect os dietary intake of calcium and phosphorus on the absorption and excretion of phosphorus in chimaera-derived sheep. Journal of Agricultural Science, v.101, p.597-602, 1983.

FISHER, L.J. A comparison of supplemental forms of phosphorus. Canadian Journal of Animal Science, v.58, p.313-317, 1978.

HOLDEN, L.A. Comparison of methods of in vitro dry matter digestibility for ten feeds. Journal of Dairy Science, v.82, n.8, p.1791-1794, 1999.

MARÇAL, W.S.; GOMES, G.P.; NASCIMENTO, M.R.L. et al. Avaliação de fontes de fósforo para nutrição mineral de bovinos. Arquivos do Instituto Biológico, v.70, n.3, p.255-258, 2003.

McDOWELL, L.R. Minerals in animal and human nutrition. New York: Academic Press, 1992. 524p.

NICODEMO, M.L.F; MORAES, S.S. Esclarecimentos sobre o uso de fontes alternativas de fósforo para bovinos. Campo Grande: Embrapa Gado de Corte, 2000. 4p. (Boletim Técnico, 37).

PEREIRA, M.S.; RIBEIRO, E.L.A.; MIZUBUTI, I.Y. et al. Carcaça e não-componentes da carcaça de cordeiros recebendo polpa cítrica úmida prensada em substituição à silagem de milho. Acta Scientarium Animal Science, v.29, n.1, p.57-62, 2007.

REID, R.L. Relationship between phosphorus nutrition of plants and phosphorus nutrition of animals and man. In: KHAWNEH, F.E.; SAMPLE, E.C.; KAMPRATH, E.J. (Eds.) The role of phosphorus in agriculture. [S.l.]: American Society of Agronomy, 1980. p.847-886.

RODRIGUES, G.H.; SUSIN, I.; PIRES, A.V. et al. Substituição do milho por polpa cítrica em rações com alta proporção de concentrado para cordeiros confinados. Ciência Rural, v.38, p.789-794, 2008a.

RODRIGUES, G.H.; SUSIN, I.; PIRES, A.J.V. et al. Polpa cítrica em rações para cordeiros em confinamento: características da carcaça e qualidade da carne. Revista Brasileira de Zootecnia, v.37, n.10, p.1869-1875, 2008b.

SALVIANO, L.M.C.; VITTI, D.M.S.S. Influência da proporção de cálcio e fósforo na dieta, nas perdas endógenas e na absorção de fósforo em ovinos. Pesquisa Agropecuária Brasileira v.33, n.3, p.349-355, 1998.

STATISTICAL ANALYSIS SYSTEM - SAS. User's guide. Cary: SAS Institute, 2002. 525p.

VITTI, D.M.S.S.; ABDALLA, A.L.; FILHO, J.C.S. Fontes alternativas de fósforo para ruminantes: absorção real e disponibilidade biológica. Arquivo Brasileiro de Medicina Veterinária e Zootecnia, v.41, n.6, p.503-510, 1989

VITTI, D.M.S.S.; ABDALLA, A.L.; MEIRELLES, C.F. Absorção real do fósforo de diferentes fontes para ovinos através do uso de radiofósforo (P-32). Pesquisa Agropecuária Brasileira v.27, n.10, p.1405-1408, 1992.

VAN SOEST, P.J.; ROBERTSON, J.B.; LEWIS, B.A. Methods for dietary fiber, neutral detergent fiber, and nonstarch polysaccharides in relation to animal nutrition. Journal of Dairy Science, v.74, p.3583-3597, 1991.

WILES, P.G.; GRAY, I.K.; KISSLING, R.C. Routine analysis of proteins by Kjeldahl and Dumas methods: review and interlaboratory study using dairy products. Journal of AOAC International, v.81, n.3, p.620-632, 1998.

WITT, K.E.; OWENS, F.M. Phosphorus ruminal availability and effects on digestion. Journal of Animal Science, v.56, n.4 p.930-937, 1983.

ZAHARI, M.W.; THOMPSON, J.K.; SCOTT, D. et al. The dietary requirements of calcium and phosphorus for growing lambs. Animal Production, v.50, p.301-307, 1990. 